\title{
Hybrid Composite Tensile Armour Wires in Flexible Risers: A Multi-scale Model
}

DOI:

10.1016/j.compstruct.2016.11.090

\section{Document Version}

Accepted author manuscript

Link to publication record in Manchester Research Explorer

\section{Citation for published version (APA):}

Gautam, M., Katnam, K-B., Potluri, V., Jha, V., Latto, J., \& Dodds, NI. (2017). Hybrid Composite Tensile Armour Wires in Flexible Risers: A Multi-scale Model. Composite Structures.

https://doi.org/10.1016/j.compstruct.2016.11.090

\section{Published in:}

Composite Structures

\section{Citing this paper}

Please note that where the full-text provided on Manchester Research Explorer is the Author Accepted Manuscript or Proof version this may differ from the final Published version. If citing, it is advised that you check and use the publisher's definitive version.

\section{General rights}

Copyright and moral rights for the publications made accessible in the Research Explorer are retained by the authors and/or other copyright owners and it is a condition of accessing publications that users recognise and abide by the legal requirements associated with these rights.

\section{Takedown policy}

If you believe that this document breaches copyright please refer to the University of Manchester's Takedown Procedures [http://man.ac.uk/04Y6Bo] or contact uml.scholarlycommunications@manchester.ac.uk providing relevant details, so we can investigate your claim.

\section{OPEN ACCESS}




\section{Accepted Manuscript}

Hybrid Composite Tensile Armour Wires in Flexible Risers: A Multi-scale Model

M. Gautam, K.B. Katnam, P. Potluri, V. Jha, J. Latto, N. Dodds

PII:

S0263-8223(16)32070-0

DOI: http://dx.doi.org/10.1016/j.compstruct.2016.11.090

Reference: COST 8051

To appear in:

Composite Structures

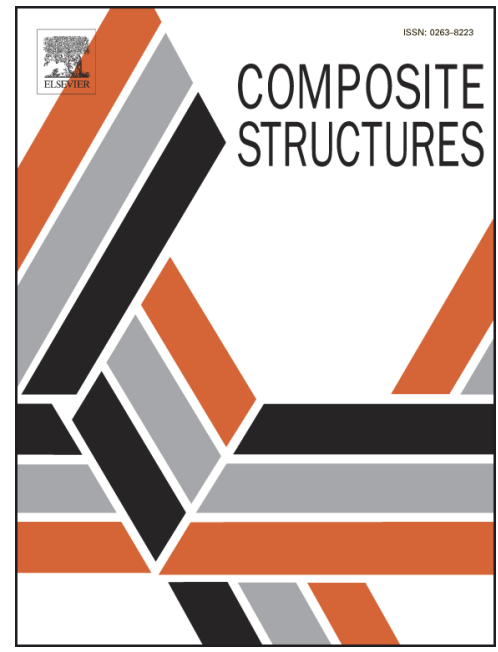

Received Date: $\quad 7$ October 2016

Accepted Date: $\quad 28$ November 2016

Please cite this article as: Gautam, M., Katnam, K.B., Potluri, P., Jha, V., Latto, J., Dodds, N., Hybrid Composite Tensile Armour Wires in Flexible Risers: A Multi-scale Model, Composite Structures (2016), doi: http://dx.doi.org/ 10.1016/j.compstruct.2016.11.090

This is a PDF file of an unedited manuscript that has been accepted for publication. As a service to our customers we are providing this early version of the manuscript. The manuscript will undergo copyediting, typesetting, and review of the resulting proof before it is published in its final form. Please note that during the production process errors may be discovered which could affect the content, and all legal disclaimers that apply to the journal pertain. 


\title{
Hybrid Composite Tensile Armour Wires in Flexible Risers:
}

\section{A Multi-scale Model}

\author{
M. Gautam 1 , K. B. Katnam², P. Potluri*1, V. Jha ${ }^{3}$, J. Latto ${ }^{3}$, N. Dodds ${ }^{3}$ \\ ${ }^{1}$ Northwest Composite Centre, School of Materials, University of Manchester, UK \\ ${ }^{2}$ School of Mechanical, Aerospace and Civil Engineering, University of Manchester, UK \\ ${ }^{3}$ GE Oil \& Gas, Newcastle upon Tyne, UK
}

\begin{abstract}
Traditional carbon-steel armour wires pose limitations (e.g. long spans, weight reduction, corrosion and fatigue) for flexible risers to operate in demanding and deeper water environments. In this context, an alternative to carbon-steel tensile armour wires is proposed recently by the authors (Gautam et al. [1]), comprising of hexagonally packed polymer composite rods with uni-directional fibres and an over-braided (i.e. bi-axial braid with high performance fibres) sleeve. These hybrid composite wires offer opportunities to tailor their mechanical properties by varying the geometrical (e.g. rod diameter, packing) and processing parameters (e.g. material selection, braid pattern) involved. In order to understand the mechanical behaviour of these hybrid composite armour wires, this paper presents a multi-scale model developed by using a combined analytical-computational approach. The multi-scale model is developed to predict the torsional and flexural behaviour of the hybrid composite wires; and the role of over-braid structural parameters, pretension and internal friction are investigated. The behaviour of the multiscale model is found to be in good agreement with the experimentally observed behaviour. After validating the multi-scale model with the experimental data available for specific configurations, parametric studies are conducted on the torsional and flexural behaviour of the hybrid composite wires to study the role of internal friction between un-bonded components and the braid tow tension in the over-braided sleeves.
\end{abstract}

Keywords: Flexible risers; tensile armour; braiding; pultrusion; multi-scale modelling.

\section{Introduction}

\footnotetext{
* Corresponding author

Email: Prasad.Potluri@manchester.ac.uk
} 
There is a growing need for innovation in the design and manufacture of flexible risers as the Oil \& Gas industry continues its efforts in exploring deeper offshore reservoirs. Flexible risers carry fluids from the facilities at the sea bed to floating units. A typical un-bonded flexible riser comprises of multiple un-bonded layered assembly, consisting of helically wound metallic wires (rectangular cross-section) as pressure and tensile armours that are inter-layered with polymeric sheaths, which help the riser to be highly compliantespecially in flexural mode. Although flexible risers are highly deformable and compliant in flexural mode, yet they provide a strong and stiff response to internal/external pressure, tension and torsion [2]. Among different layers in a traditional un-bonded flexible riser, the tensile armour is an integral part consisting of metallic (typically carbon-steel) wires with a rectangular cross-section, which resists tensile, flexural and torsional loads [3-5].

Major failures in flexible risers are often driven by the damage and failure of tensile armours [6], which include crack nucleation, tensile fatigue, radial buckling, and lateral buckling. Moreover, carbon-steel, which is the most widely used material for tensile armour wires, is more prone to environmental degradation (e.g. corrosion, hydrogen sulphide induced stress cracking [7]), and thus the type of carbon-steel to be used depends upon the service environment and conditions. Recent works [8-11] have shown great potential for carbon fibre thermoplastic and thermoset matrix composites (similar dimensions to metallic wires) in replacing metallic tensile and hoop armours. These composites show higher tensile strength and fatigue, excellent corrosion resistance, and enable significant overall weight reduction of flexible riser systems. However, these composite wires develop high strains when wound in the riser, limiting the usable thickness and resistance to brittle damage/fracture.

Due to the limitations of carbon-steel material and the recently introduced carbon composite tensile armour wires, a novel hybrid composite armour wire (as shown in Fig. 1) is proposed by Gautam et al. [1]. These hybrid composite armour wires consist of carbon and vinyl ester pultruded rods, stacked in form of hexagonal closed packing, completely un-bonded to each other, but held together by an over-braided ultrahigh molecular weight polyethylene (UHMW-PE) fibres-commercially known as Dyneema. The combination of braiding and pultrusion process together can help in continuous production of tensile armour wires. The hybrid composite armour wires aim not only to provide lower torsional and flexural rigidities but 
also to ensure high tensile stiffness and strength. The structure is analogous to the structure of flexible riser itself, comprising of multiple un-bonded components.

This paper, with emphasis on computational modelling, is an extension to the experimental work conducted by the authors in Gautam et al. [1]. A multi-scale model is developed by using a combined analyticalcomputational approach for the hybrid composite armour wires to study the torsional and flexural behaviour as a function of over-braid parameters, internal friction, and braid tow pre-tension. The over-braided sleeve is modelled as a homogenised orthotropic shell; and the composites rods are modelled as homogenised orthotropic solids. These homogenised elastic properties are then used to develop a multi-scale model for the hybrid composite wires. The internal friction between composite rods as well as the rods and the shell (i.e. homogenised over-braid sleeve) are also incorporated in the model. Moreover, braid tow pre-tension is accounted for in the form of an equivalent hoop pressure and then exerted on the composite rods. The combined analytical-computational approach proposed reduces computational effort as micro- and mesoscale computational models are avoided. The experimental response is used to validate the model and then further employed for parametric analyses.

\section{Materials and Manufacturing}

The procedure followed for the manufacturing and testing of the hybrid composite armour wires is reported by the authors in Gautam et al. [1]. The manufacturing process of the hybrid composite wires involved overbraiding of hexagonally packed pultruded rods, where each rod had a diameter of $4 \mathrm{~mm}$. This form of packing provides the highest packing efficiency, and densest packing for straight cylinders when their axes are parallel [12]. This form of packing also extends the interaction of energy between the rods [13] and geometrically all the pairs of neighbouring axes are located at a constant distance from each other. Prior to the braiding process, the packed rods were taped at the ends and no adhesive is used to bond the rods together. For over-braiding the hexagonally packed rods, regular (2/2) and diamond (1/1) braid topologies are used, and three different braid angles $\left(30^{\circ}, 45^{\circ}\right.$ and $\left.55^{\circ}\right)$ are employed. The hexagonal packed rods are over-braided using 24 and 48 carrier braiding machines. All 24 carriers on a 24 carrier machine are used to produce a regular (2/2) braid topology, and only 24 carriers on a 48 carrier machine are employed to obtain a 
diamond (1/1) braid topology. These two configurations are considered to study the effect of braid topology on the flexural and torsional behaviour of the hybrid composite wires.

The braid structural parameters are given in Table 1. These parameters are measured physically and through image analysis. The crimp phenomenon in a braid refers to the waviness or undulation of a tow as a result of interlacement between tows. Braid crimp can be quantified (see Eq. 1) as the ratio of the difference between the length of the crimped tow $\left(L_{c}\right)$ and the length of the non-crimped tow $\left(L_{n c}\right)$ to that of the length of the crimped tow $\left(L_{c}\right)$. The braid crimp percentage $(C)$ for all the braided configurations is calculated using Eq. 1 . The crimp factor $(\alpha)$ derived from the crimp ratio (A) (see Eqs. $2 \& 3$ ) can be used to calculate the crimp angle $(\beta)$, as in Eq. 4, that the tows make upon crossing over and under the other tows during braiding. The following equations are taken from ISO 7211-3 [14].

$C=\left(\frac{L_{c}-L_{n c}}{L_{n c}}\right) \times 100$

$A=L_{c} / L$

$\alpha=\sqrt{A-1}$

$\beta=\tan ^{-1} \alpha$

When the braid angle is increased from $30^{\circ}$ to $45^{\circ}$, it can be observed from Table 1 that the braid crimp increased by $12 \%$ for the diamond braid and $38 \%$ for the regular braid. When the braid angle is increased from $45^{\circ}$ to $55^{\circ}$, the braid crimp increased by $79 \%$ for the diamond braid and $52 \%$ for the regular braid. This increase in braid crimp with an increase in braid angle is thought to have caused by the increase in braid density, which increases as more tows are deposited per unit length [7]. The effect of braid topology on braid crimp is found to be significant for $30^{\circ}$ and $55^{\circ}$ braid angles, where a decrease of $18 \%$ in braid crimp for $30^{\circ}$ braid angle and a further decrease of $14 \%$ for $55^{\circ}$ braid angle is observed when the topology is varied from diamond to regular. However, for $45^{\circ}$ braid, a small decrease in braid crimp, only about $0.8 \%$, is observed as 
the topology is varied from diamond to regular. For the diamond and regular braids produced using the same number of tows, the same length of tow in a regular braid experiences a lower crimp as compared to that of the diamond braid due to its higher float length.

\section{Mechanical Characterisation}

\subsection{Flexural Behaviour}

As there were no specific standard for testing material systems or structures that are similar to the proposed hybrid wires, from the available standards [15-17] related to fibre-reinforced composite materials, ASTM D7264 [13] is used as it contained test procedures both for three-point and four-point flexural tests. The specimens are taped within $10 \mathrm{~mm}$ at both ends using high performance tape, depicting flexural behaviour of long lengths armour wires. For the two types of flexural tests, a span-to-thickness ratio of 32:1, i.e. a span length of $352 \mathrm{~mm}$, is chosen for the hybrid wires. The total specimen length of $500 \mathrm{~mm}$ is used, conforming to the standard specification, which suggests $10 \%$ extra specimen length at the ends. The cross-head speed of $5 \mathrm{~mm} / \mathrm{min}$ as recommended is used with a $10 \mathrm{kN}$ load cell. The flexural tests are conducted up to a maximum mid-point deflection of $55 \mathrm{~mm}$; however, with an emphasis on the elastic response of the hybrid wires, the results are only reported up to $2.5 \mathrm{~mm}$ mid-point deflection.

\subsection{Torsional Behaviour}

The torsion tests, with a gauge length of $100 \mathrm{~mm}$, are carried out up to a maximum limit of $400 \% \mathrm{~m}$ for the hybrid wires [1]. A total of 5 specimens for each configuration (see Table 1) are tested. The results are only reported up to $3 \% \mathrm{~m}$ as the emphasis is on the elastic response of the hybrid wires. The rods and over-braid sleeve are bonded together at the ends (approximately $20 \mathrm{~mm}$ near each end) using an epoxy adhesive; and V-grips are used for the tests. A cross-head rotation speed of $1 \%$ sec is used.

\section{Multi-scale Modelling Methodology}


A multi-scale model is developed by using a combined analytical-computational approach for the hybrid composite armour wires. An overview of the methodology employed is shown in Fig. 2. The aim is to study the torsional and flexural behaviour as a function of over-braid parameters, internal friction, and braid tow pre-tension. The over-braided sleeve is modelled as a homogenised orthotropic shell; and the composites rods are modelled as homogenised orthotropic solids. The homogenised elastic properties, which are obtained from analytical models for the composite rods (i.e. using a micro-mechanical model) and the overbraid sleeve (i.e. using a meso-mechanical model, which is based on the model proposed for a tri-axial braids in [1]), are used to develop a multi-scale model for the hybrid composite wires. The internal friction between composite rods as well as the rods and the shell (i.e. homogenised over-braid sleeve) is incorporated in the model. Moreover, braid tow pre-tension is accounted for in the form of an equivalent hoop pressure and then exerted on the composite rods. The combined analytical-computational approach proposed could considerably reduce computational effort as micro- and meso-scale computational models are not considered.

The composite rods are modelled as transverse isotropic solids, and their elastic properties are obtained experimentally wherever possible, while the other properties are predicted using micro-mechanical models by using the properties of fibre, matrix and their volume fraction in the composite. For the bi-axial overbraided sleeve, which is modelled as an orthotropic shell, the homogenisation procedure for the elastic properties of over-braided sleeves is relatively complicated as the properties of the braid will be different from the properties of the individual fibre tows used to produce the braid architectures. There are several experimental and analytical studies conducted on braided structures [19-23], especially with regard to biaxial braided sleeves with and without a core. However, none of them can directly be employed to predict homogenised properties that can represent the over-braided sleeve as an equivalent orthotropic shell for the current multi-scale analysis. In this regard, an alternative approach is employed here by using the analytical approach presented in [18] for tri-axial braided composites.

\subsection{Composite Rods: A Micro-mechanical Model}


The uni-directional composite rods, which are stacked in the form of a hexagonal closed pack for producing the hybrid wires, are considered to be transversely isotropic. As the composite rod, made of carbon fibre and vinyl ester with high fibre volume fraction, the composite rod satisfies the condition of transverse isotropy. The values of $E_{11}$ and $G_{12}$ are determined experimentally following ASTM D3916 [24], and are given in Table 2. The remaining elastic properties of the composite rods are calculated using micro-mechanical models [26-28] considering the fibre volume fraction as well as the material properties of fibre and matrix (given in Table 2).

\subsection{Over-braided Sleeve: A Meso-mechanical Model}

A meso-scale analytical model, which is based on the model proposed for tri-axial braided composites in [14], is used to estimate the homogenised orthotropic properties of the over-braided sleeve with bi-axial regular and diamond braid topologies. The analytical model [18], which accounts for crimp angle, geometrical characteristics and fibre volume fraction, predicts the effective properties of tri-axial braided composites by combining the stiffness contributions of the axial tows, the braid tows and the matrix. As the over-braid sleeves used in the hybrid wires are dry bi-axial braids, the volume fraction of the axial tows and the matrix surrounding the braid tows are assumed to be zero in order to estimate the homogenised orthotropic properties. The model proposed in [18], assumes fibre tows as composite rods. In order to satisfy this condition, the fibre volume fraction in a tow (assumed to be a composite rod) is assumed to be $70 \%$. The matrix chosen for the tow is high density poly-ethylene with low tensile and shear stiffness $(E=0.70 \mathrm{GPa}$ and $v=0.40$ obtained from $[32,33])$. The polyethylene based matrix is also chosen because the braid fibres are also poly-ethylene based (UHMW-PE fibres). The elastic properties of UHMW-PE tows were calculated using micro-mechanical models and are reported in Table 4. The elastic properties of the fibres in the tow are also given in Table 4, which are assumed to be transversely isotropic.

First, the model transforms the stiffness matrix of a braid tow by incorporating the crimp angle, and then transforms the transformed stiffness matrix of the tow (inclusion of crimp) by including the braid angle $\pm \theta$. This transformed stiffness matrix, which includes both the crimp angle and the braid angle, is then used for calculating the braid stiffness by including the structural parameters of the braid. This is represented in Eq. 5, 
where $S_{i j}^{b p}$ and $S_{i j}^{b m}$ are the compliances of bi-axial tows for a particular braid angle $\left(S_{i j}^{b p}\right.$ for $+\theta$ and $S_{i j}^{b m}$ for $\theta$ ). Moreover, $V_{b}$ is the percentage of bi-axial tows and $V_{t}$ is the volume of the braid unit cell.

$S_{i j}=\left[\left(\frac{V_{b}}{2 V_{t} S_{i j}^{b p}}\right)+\left(\frac{V_{b}}{2 V_{t} S_{i j}^{b m}}\right)\right]^{-1}$

$$
(i, j=1,2,3,4,5,6)
$$

$\bar{E}_{11}=\frac{1}{S_{11}}$

$$
\bar{E}_{22}=\frac{1}{S_{22}}
$$$$
\bar{E}_{33}=\frac{1}{S_{33}}
$$

$\bar{G}_{23}=\frac{1}{S_{44}} ;$

$\bar{G}_{13}=\frac{1}{S_{55}} ;$

$$
\bar{G}_{12}=\frac{1}{S_{66}}
$$

$\bar{v}_{12}=-\frac{S_{12}}{S_{11}} ;$

$$
\bar{v}_{13}=-\frac{S_{13}}{S_{33}} ;
$$$$
\bar{v}_{23}=-\frac{S_{23}}{S_{22}} ;
$$

The homogenised properties of the over-braid sleeves, calculated using the meso-scale analytical model, are given in Table 5. As it can be seen, for the braid angles considered (i.e. from $30^{\circ}$ to $55^{\circ}$ ), an increase in the braid angle leads to a decrease in the axial modulus as expected. The effect of braid topology on the axial modulus is also observed. Regular braid topology provides a higher axial modulus because of a lower crimp angle and float length. Higher crimp values as in the case of the diamond braid topology, offer higher extensibility, thereby reducing the resultant stiffness of the sleeve as compared to the regular braid topology. A decrease in the Poisson's ratio (1-2 plane) with an increase in braid angle is also expected as an increase in braid angle increases the longitudinal strain and decreases the transverse strain. An increase in braid angle leads to a decrease in shear stiffness, which is expected to be a maximum for a $45^{\circ}$ braid angle when compared to the values for $30^{\circ}$ and $55^{\circ}$ braid angle as reported in [37]. The reason for this unexpected trend is due to the sensitivity of the analytical model towards crimp angle, which increases with an increase in the braid angle. 


\subsection{Hybrid Composite Wires: A Multi-scale Model}

The torsional and flexural response of the hybrid wires is analysed using a multi-scale approach. The homogenised properties obtained for the composite rods and the over-braid sleeves are used in developing the model. The model is implemented in Abaqus/Standard 6.13.

\subsubsection{Geometry and Mesh}

To model the hybrid wires, the individual composite rods are modelled as an orthotropic continuum and the over-brad sleeve as an orthotropic shell. The material orientation employed for the composite rods, the overbrad sleeve (i.e. shell), and the assembly are shown in Fig. 3. A 4-node general purpose shell element (i.e. S4) is used for modelling the over-brad sleeve. For the composite rods, an 8-node continuum element (i.e. C3D8) is employed. A hexahedral mesh was chosen as it offers numerical advantages [38-40]. The mesh sensitivity studies are carried out prior to parametric studies.

\subsubsection{Interaction Properties}

The interaction between the composite rods as well as the composite rods and the over-brad sleeve are incorporated in the model. To account for internal friction, it is important to measure the coefficient of friction between the composite rod surfaces $\left(\mu_{r}\right)$ and also the over-braided sleeve surface (modelled as a shell) and the composite rod surfaces $\left(\mu_{s}\right)$. As a matrix-rich layer is observed at the surface of the pultruded rods used in this study (see Fig. 4) the inter-rod friction behaviour is assumed to be dictated by the matrixrich layer. The coefficient of friction between solidified vinylester resin is approximately 0.49 [41], and is thus used as the coefficient of friction $\left(\mu_{r}\right)$ for modelling the inter-rod friction. The coefficient of friction for the braid fibres is known to be very low, offering abrasion resistance. The value of $\mu_{s}$ is experimentally measured using the test setup shown in Fig. 5 (using tow tensions $T_{1}, T_{2}$, and the wrap angle, $\gamma$ ) and Eq. 7 , and is found to be approximately 0.062 .

$\mu_{s}=\frac{\ln \left(T_{2}\right)}{\gamma \ln \left(T_{1}\right)}$ 
The interaction behaviour, i.e. the contact between the composite rods, and also between the shell and the rods, is defined using the master and slave surface definitions in Abaqus/Standard 6.13 together with hard contact for the normal response and with friction for the tangential response. The hard contact relationship minimizes the penetration of the slave surface into the master surface at the constraint locations and does not allow the transfer of tensile stress across the interface. The hard contact is defined between the rods, and between the shell and the rods. It is important to note that the hybrid wires are held together by the overbraid sleeve (shell) which exerts hoop pressure (tow tension inside the braid) on the hexagonally packed rods. To account for this phenomenon, an additional load step is introduced by which hoop pressure is incorporated into the model. The hoop pressure $\left(p_{0}\right)$ is calculated using Eq. 8 presented in [42], which transforms the braid tow pre-tension into an equivalent hoop pressure for a single bi-axial braid layer (representing the over-braided sleeves in the hybrid wires). The Eq. 8 is in general applicable to filament wound structures as well as braided structures [43].

$p_{0}=\left[\frac{T \sin ^{2} \theta}{r_{1} w}\right]+\left[\frac{T \sin ^{2} \theta}{r_{2} w}\right]$

$p_{0}=\left[\frac{\pi T \sin ^{2} \theta}{(r \pi+6 r) w}\right]+\left[\frac{2 \pi T \sin ^{2} \theta}{(2 \pi r+12 r+t \pi) w}\right]$

From Eq. 8, the equivalent hoop pressure $\left(p_{0}\right)$ can be calculated for a specific value of tow tension inside the braid $(T)$, braid angle $(\theta)$, tow width $(w)$ of the bi-axial braid sleeve for a circular cross-section. The distance from the centre of the core to the mid-plane of the biaxial sleeve is $r_{l}$, and the radius of the core is $r_{2}$. The Eq. 8 is modified for the cross-section of the hybrid wire and is expressed in Eq. 9, where the equivalent hoop pressure is calculated using the tow tension inside the braid $(T)$, the tow width $(w)$, the braid angle $(\theta)$, the braid thickness $(t)$ and the radius of the composite rods $(r)$. Note that the tow tension $(T)$, see Eqs. 8-9, is different from the tow tensions $T_{1}$ and $T_{2}$, which are used to calculate the coefficient of friction value. The equivalent hoop pressure values for different braid configurations are given in Table 7. As it can be seen, for a braid angle of $55^{\circ}$, in the case of diamond and regular braid topologies, the equivalent hoop pressure is a maximum due to the smaller tow widths in both diamond and regular braid topologies. Comparing the 
equivalent hoop pressure values between the diamond and regular braid topologies, it can be seen that the diamond braid topologies impart higher hoop pressure due to lower tow width values (see Table 6).

\subsubsection{Boundary Conditions}

The torsional and flexural behaviour of the hybrid wires are investigated using two different loading and displacement conditions. The boundary conditions used for predicting the elastic behaviour under torsion, three-point flexure and four-point flexure are shown in in Fig. 6.

For torsion, the length of the model used is the length of the experimental test specimens (i.e. $100 \mathrm{~mm}$ ). Using kinematic coupling constraints, which are used to constraint all the surface nodes at edges to reference nodes, the boundary conditions (i.e. apply rotation to one reference node and fixing the other reference node) are applied to the model. A twist of $3 \% \mathrm{~m}$ is applied to the first reference, whilst all degrees of freedom are constrained at the second reference node.

For flexure, using the symmetric conditions, only half of the specimen length tested is modelled (see Figs. 6b $\& 6 c)$. As the test specimen length is $352 \mathrm{~mm}$, the length of the model is $176 \mathrm{~mm}$. The load and support pins used in the experimental test setup are simplified and modelled as contact lines (see Figs. $6 \mathrm{~b} \& 6 \mathrm{c}$ ). For the case of three-point flexure, a downward displacement of $2.5 \mathrm{~mm}$ is applied at the top edge of the shell which is in contact with the load pin (see Fig. 6b). At the other cross-sectional plane, in contact with support pin, the rods and the shell which are in contact with the support pin are constrained to avoid the nodal displacements which allow the experimental boundary conditions to be implemented. The lateral displacement constraints are used to avoid any rigid body motions. Similar boundary conditions are also employed for four-point flexure, with an exception on the load pin location where the displacement is applied. A displacement of $2.0 \mathrm{~mm}$ is applied onto the top face of the shell at the mid-span cross-section as shown in Fig. 6c. In addition, to incorporate the effect of braid tow pre-tension, an equivalent hoop pressure (estimating for a given braid tow tension) is applied on the shell in the model. 


\section{Results and Observations}

The multi-scale model is used to investigate the effect of the structural parameters of the over-braid sleeve on the flexural and torsional behaviour of the hybrid wires. Two different pre-load conditions are considered: (a) with the equivalent hoop pressure and (b) without the equivalent hoop pressure applied by the over-braid sleeve on the rod bundle by using the interaction properties and the equivalent hoop pressure discussed in Section 4.3.2.

\subsection{Torsional behaviour}

The experimental torsional response of the hybrid composite wires is compared with the predicted torsional response for different over-braded sleeve configurations and shown in Fig. 7. The curves shown in Fig. 7 are normalised using the experimentally measured torque for the diamond braid topology with $30^{\circ}$ braid angle at $3 \% \mathrm{~m}$ rotation. As seen in Fig. 7, the experimental and predicted responses are in good agreement, with a maximum deviation of nearly $8 \%$ for $30^{\circ}$ braid angle with the diamond braid topology (with the equivalent hoop pressure) because of high in-pane shear stiffness. From the torsion experiments, the highest torsional rigidity is observed for $45^{\circ}$ braid angle, followed by $30^{\circ}$ and $55^{\circ}$ braid angles. The highest torsional rigidity of $45^{\circ}$ braid configuration conforms to the trend predicted by the composite laminate theory that predicts the highest in-plane shear modulus $\left(G_{12}\right)$ for $45^{\circ}$ ply-orientation, followed by $30^{\circ}$ and $55^{\circ}$ ply-orientations [37]. In a study conducted in [44] to determine the effect of braid angle upon the torsional properties of bi-axial braided composite tubes, it was observed that specimens with $45^{\circ}$ braid angle provided the highest shear modulus among two other braid angles of $31^{\circ}$ and $65^{\circ}$. In addition, in a study conducted in [45] on braided pultruded composites, specimens with $45^{\circ}$ braid angle provided the highest shear modulus, followed by specimens with $30^{\circ}$ and $55^{\circ}$ braid angles.

The effect of braid topology is observed to have a considerable effect on the torsion tests. The hybrid wires with regular braid topologies offered higher torsional rigidities, for all three braid angles used, because of lower crimp values, when compared with the hybrid wires with diamond braid topologies. The effect of braid angle is found to be significant; the highest torsional rigidity is predicted for $30^{\circ}$ braid angle, followed by $45^{\circ}$ and $55^{\circ}$ braid angles, for both diamond and regular braid topologies. This is partly in contradiction with 
the experimental response, the highest torsional rigidity is observed for $45^{\circ}$ braid angle, followed by $30^{\circ}$ and $55^{\circ}$ braid angles. This is because of the highest shear properties predicted for $30^{\circ}$ braid angle (see Table 5), followed by $45^{\circ}$ and $55^{\circ}$ braid angles. The homogenisation techniques used for the bi-axial over-braided sleeve is sensitive to crimp angle that increases with an increase in braid angle. However, the multi-scale model successfully predicts the effect of braid topology; the regular braid at all three braid angles offered high torsional rigidity as compared to the diamond braid topology, which is in agreement with the experimental behaviour.

The stress distribution in the composite rods (the over-braided sleeve/shell is not shown) under torsion is shown in Fig. 8 at 3\% twist: (a) without the equivalent hoop pressure (Fig. 8a) and (b) with the equivalent hoop pressure (Fig. 8b). As shown in Fig. 8 a \& 8b, although the peak stresses in the rods are very small $(<3$ MPa in Fig. 8a and $<13$ MPa in Fig. 8b), the hoop pressure has an effect on the stress distribution as it introduces internal friction between the rods. Moreover, the effect of equivalent hoop pressure is observed to be negligible on the normalised curves shown in Fig. 7 , where a marginal increase $(0.8 \%$ on average $)$ in torsional rigidity is seen for both diamond and regular braid topologies. However, this effect could be considerable when the coefficient of friction as well as the length of the specimen is large.

\subsection{Flexural behaviour}

\subsubsection{Three-point flexure}

The comparison of the experimental and predicted response of the hybrid composite wire specimens to threepoint flexure for different braid configurations is shown in Fig. 9. The curves are normalised with the bending moment applied in the case of $30^{\circ}$ braid angle and diamond braid topology at $0.25 \mathrm{~m}^{-1}$ curvature. As observed in Fig. 9, a good agreement is found between the experimental and predicted behaviour when no hoop pressure is incorporated in the analysis. However, when the equivalent hoop pressure is incorporated, a small increase in stiffness compared to the case with no hoop pressure is observed between the experimental and multiscale model behaviour, with a maximum deviation of $11 \%$ for $55^{\circ}$ braid angle with diamond braid topology because of highest hoop pressure value. 
The reason for higher deviations between the experimental and multiscale model behaviour could be due to the experimental test procedure followed. The test specimens are cut from very long hybrid wires and then taped at the ends for applying the boundary conditions. This could have altered the effective hoop pressure exerted by the over-braid on the rod bundles, especially at the specimen ends. This could also be the reason for a better correlation observed between the predicted (when no hoop pressure is applied) and experimental behaviour. If specimen lengths which are longer than the minimum requirement of the test standard used (which recommends a minimum extra length of $10 \%$ of span length at both the ends), the effects arising from the specimen preparation are expected to be considerably reduced.

As observed in Fig. 9, experimentally, marginal changes in flexural behaviour are observed with the change in braid angle. Such minor change could be due to the dry nature (no resin matrix) of the over-braid sleeve. When the braid is impregnated with resin (i.e. in rigid composite form), its effect can be more pronounced; and an increase in the braid angle could lead to a decrease in flexural rigidity as presented in [44]. Also due to the resin impregnation, there is no hoop pressure exerted by braid sleeve on the core it is braided on, as they are separated by the matrix. The effect of braid angle and braid topology is captured with the help of the multi-scale model which otherwise could not be observed experimentally. As expected (the trend observed in [44]), an increase in braid angle leads to a decrease in flexural rigidity (again marginal) in absence of hoop pressure. However as the hoop pressure is incorporated an increase in flexural rigidity is observed as the braid angle is increased, due to increase in hoop pressure (which increases as braid angle increases). The diamond braid topology depicted higher flexural rigidities as compared to regular braid topologies, due to higher hoop pressure values that stem from lower tow widths as compared to regular braid structures.

The stress distributions in the hybrid wires under flexure are shown in Fig. 10, where the effect of hoop pressure can be observed, at $0.25 \mathrm{~m}^{-1}$ curvature (i.e. $2.5 \mathrm{~mm}$ mid-span deflection), for both the cases: (a) without the equivalent hoop pressure (Fig. 10a), and (b) with the equivalent hoop pressure (Fig. 10b). For the cross-sectional plane in contact with the load pin (i.e. at mid-span), similar stress distributions are observed for the rods, with stress concentrations at the top and bottom fibres in each rod due to bending. The overbraid shell shows lower stresses in comparison with the rods, primarily due to its lower stiffness in comparison to the composite rods. 
The cross-section in contact with the support pin has the highest stress concentration on the bottom rods at the contact points and the shell edge in contact with the support pin. Note that these stress concentrations at the support pin are due to the test conditions and thus may not be relevant to the in-situ stress states in long tensile armours wires. The higher stresses, in the presence of equivalent hoop pressure, contributed to the bending moment versus curvature curves in Fig. 9, where in the case of diamond topology, an increase of nearly $2.8 \%$ (average) is observed. However, in the case of regular topology, a smaller increase of $1.7 \%$ (average) is seen with the equivalent hoop pressure. The increase in flexural rigidity in the case of diamond topology is due to the lower tow width in comparison to that of the regular braid topology.

\subsubsection{Four-point flexure}

The experimental behaviour of the hybrid wires is compared with the multi-scale model behaviour for different braid configurations and is shown in Fig. 11 under four-point flexure. The curves are normalised with the bending moment applied in the case of $30^{\circ}$ braid angle and diamond braid topology at $0.16 \mathrm{~m}^{-1}$ curvature (i.e. mid-span deflection of $2.5 \mathrm{~mm}$ ). As observed in Fig. 11, a good agreement is found between the experimental and multi-scale model behaviour when no hoop pressure is incorporated into the model. However, when the equivalent hoop pressure is incorporated, some deviation in stiffness, compared to the case with no hoop pressure, is observed between the experimental and multi-scale model behaviour, with a maximum deviation of $19.5 \%$ for $55^{\circ}$ braid angle with diamond topology, due to highest hoop pressure value. The reason for this deviation between the experimental and predicted behaviour could be due to the experimental test procedure followed, similar to the case of three-point flexure. However, the reason for the higher deviation, compared to the predicted three-point flexural behaviour, is because the load point in fourpoint flexure is at half the distance compared to three-point flexure, reducing the effect of hoop pressure. This could also be the reason for a better correlation observed between the predicted (when no hoop pressure is applied) and experimental behaviour. 
As observed in Fig. 11, marginal changes in flexural behaviour are observed with the changes in braid angle and topology. However, the effect of braid angle and topology is captured by the multi-scale model. As expected (trend observed in [44]), an increase in braid angle led to a decrease in flexural rigidity, when no hoop pressure is present. However, as the hoop pressure is incorporated an increase in flexural rigidity is observed as the braid angle is increased, due to increase in hoop pressure values. The diamond braid topology showed higher flexural rigidities in comparison with regular braid topology, just as in case of three point flexural, due to higher hoop pressure values. The stress distributions are shown in Fig 12, where the effect of the equivalent hoop pressure can be observed, at $0.16 \mathrm{~m}^{-1}$ curvature (i.e. mid span deflection of 2.5 $\mathrm{mm}$ ), for both the cases: (a) without hoop pressure (Fig 12a), and (b) with the equivalent hoop pressure (Fig $12 \mathrm{~b})$. For the cross-sectional plane in contact with the load pin, stress concentrations are observed in the shell and rods as shown in Figs. 12a and 12b. For the cross-section at the mid-span, the rods show a similar stress distribution. The higher stresses, in the presence of the equivalent hoop pressure, contributed to the bending moment versus curvature curves in Fig 11, where a considerable effect of the equivalent hoop pressure is observed for both diamond and regular braid topologies.

\section{Discussion}

The multi-scale modelling methodology used for the torsional and flexural response of the hybrid composite wires is validated with the experimental data in Section 5. Although the model is developed based on several assumptions at each scale involved, the predicted elastic behaviour of the hybrid wires is found to be in good agreement with the experimental behaviour. The validated multi-scale model is further used to understand the effect of internal friction between the rods, and between the over-braid sleeve and the rods. A parametric study is conducted using the four-point flexural and torsional models. The range of the coefficients of static friction considered is between two extreme values (i.e. 0 and 1), although the experimental values could be close to 0 for the material systems considered in the hybrid wires. The effect of friction is shown in Fig. 13 for one of the braid configurations (i.e. $45^{\circ}$ braid angle with diamond topology), where the equivalent hoop pressure is incorporated (note that in the absence of the equivalent hoop pressure, the effect of friction was observed, as expected, to be negligible). The flexural and torsional rigidities in Fig. 13 are normalised by 
using the rigidities obtained from the experimentally measured coefficients of friction as the base values for both torsion and flexure.

As can be seen in Fig 13, the predicted torsional and flexural rigidities are observed to be relatively low when the coefficients of friction are assumed to be 0 (i.e. assuming no friction) between the unbonded components. Moreover, as expected, the predicted rigidities are observed to be relatively high when the coefficients of friction between the components are assumed to be 1 . When the coefficient of friction between the over-braid sleeve and the rods (i.e. $\mu_{s}$ ) is assumed to be very small and the coefficient of friction between the rods (i.e. $\mu_{r}$ ) is varied from 0 to 1 , the effect of inter-rod friction in the case of flexure is observed to be considerable ( $7 \%)$, while the effect of inter-rod friction in the case of torsion is found to be negligible $(<1 \%)$. Similarly, the effect of friction between the over-braid sleeve and the rods is found to be negligible $(<1 \%)$ on the torsional rigidity and considerable on the flexural rigidity (i.e. $\sim 4 \%$ increase when $\mu_{s}$ is varied from 0.06 to 0.49 for a constant value of $\mu_{r}$ (i.e. 0.49), see Fig. 13. The comparison of the predicted torsional and flexural rigidities for the other combinations of $\mu_{s}$ and $\mu_{r}$ values studied is shown in Fig. 13.

The multi-scale model is also used to understand the effect of specimen length on the predicted torsional and flexural rigidities. In Fig. 14, the rigidities are normalised by using the experimental rigidities obtained with corresponding span/gauge lengths. As the gauge length increased, a decrease in torsional rigidity was observed; a drop of $\sim 10 \%$ in the predicted torsional rigidity is observed as the length increased from $100 \mathrm{~mm}$ to $200 \mathrm{~mm}$, followed by a drop of $\sim 2 \%$ as the length increased to $300 \mathrm{~mm}$, and beyond $300 \mathrm{~mm}$ a stable response is predicted. In the case of flexure, an increase in the model length (span length) causes an increase in flexural rigidity. As shown in Fig. 14, as the span length is increased from $100 \mathrm{~mm}$ to $200 \mathrm{~mm}$, an increase of $\sim 16 \%$ is observed; and with further increase in the span length to $300 \mathrm{~mm}$ and beyond, an increase of $18 \%$ and $22 \%$ in flexural rigidity compared to that of a spam length of $100 \mathrm{~m}$ is observed. It can be seen that the span-to-thickness (or a characteristic cross-sectional dimension) ratio should be used carefully for mechanical testing and for computational modelling of hybrid composite wires. As in the case of lower spanto-thickness ratios, the response can be governed by both shear and bending rather than by bending alone. 
The effect of span length was studied in [46] where similar behaviour is observed, with short spans offering significantly low flexural stiffness compared to long span lengths.

While the developed multi-scale model is found to be a useful approach that can be employed to conduct parametric studies in order to understand the torsional and flexural behaviour of hybrid wires, it should be noted that this modelling approach cannot be directly applied to understand the behaviour of the hybrid wires at higher strains (when braid tows begin to shear significantly and can change the associated braid angles). However, the model can successfully be used to predict elastic properties of hybrid wires at lower strains (when the shearing of braid tows is negligible). But, by determining the rate of change of braid angle with increasing strain, a modified approach could be defined to apply the model to higher strains levels.

\section{Conclusions}

A multi-scale modelling methodology is developed for predicting the torsional and flexural response of the hybrid composite tensile armour wires proposed by the authors in Gautam et al. [1] as an alternative to traditional carbon-steel tensile armour wires for flexible risers. The hybrid composite wires, which consist of a hexagonal pack of pultruded rods and are held together by an over-braided sleeve, are analysed using a combined analytical-computational approach, which incorporates a combination of micro- and meso-scale analytical models in a macro-scale computational model. The internal friction between the unbonded composite components of hybrid wire is accounted for into the multi-scale model. An equivalent hoop pressure is defined to incorporate the pressure exerted by the over-braid sleeve onto the packed rods as a result of braid tow pre-tension. The predicted elastic torsional and flexural responses are observed to be in good agreement with the experimental response.

For the material and structural parameters considered in this study and from the multi-scale model, the flexural behaviour of hybrid wires is observed to be controlled primarily by the composite rods and the hoop pressure exerted by the braid shell, whilst the torsional response by the composite rods and braid shear stiffness. From the experimental studies conducted in Gautam et al. [1], although the effect of braid angle and topology on the flexural response of hybrid wires is found to be considerable, the trends observed are 
inconclusive. However, the parametric studies conducted using the validated multi-scale model predicts a decrease in flexural rigidity with an increase in braid angle, when no hoop pressure is present; conversely an increase in flexural rigidity with an increase in braid angle when hoop pressure is present. The multi-scale model also predicts a higher flexural rigidity for the regular braid topologies when compared with the diamond braid topologies when no hoop pressure is present, and conversely when hoop pressure is present. The effect of hoop pressure on the flexural response of hybrid wires is found to be considerable, resulting in higher flexural rigidities due to the hoop pressure exerted by the over-braid sleeve on the rods. In the case of torsion, the model predicts a decrease in torsional rigidity with an increase in braid angle, which is in part agreement with the experimental results (i.e. the maximum torsional rigidity is observed for $45^{\circ}$ braid angle followed by $30^{\circ}$ and $55^{\circ}$ braid angle) due to the sensitivity of the model towards crimp in the over-braid sleeves (crimp increases with increasing braid angles). From the predicted torsional responses, a considerable effect of braid topology is found, with relatively higher torsional rigidity for regular braid topology. The effect of hoop pressure on the torsional response of hybrid wires was found to be negligible.

For the material and structural parameters considered and from the parametric studies conducted (see Section 6), it is observed that: (a) the internal friction (i.e. $\mu_{s}$ and $\mu_{r}$ together with the equivalent hoop pressure) between the unbonded components of the hybrid wire considerably increases the flexural rigidity (while increase in torsional rigidity is negligible), and (b) the specimen length (to be considered for experimental tests) can affect the measured flexural and torsional rigidity for a given cross-sectional geometry (i.e. the ratio between the span length to the characteristic cross-sectional dimension).

In general, although the develop multi-scale model is based on several assumptions at each scale involved, as the predicted torsional and flexural responses are in good agreement with the test data, the multi-scale approach presented is computationally less expensive and could be applied to similar composite structures.

\section{Acknowledgements}

The authors would like to thank the staff of University of Manchester and GE Oil \& Gas (United Kingdom), for all their help and support for this work. 


\section{References}

1. Gautam M, Potluri P, Katnam KB, Jha V, Leyland J, Latto J. Hybrid composite wires for tensile armours in flexible risers: Manufacturing and mechanical characterisation. Composite Structures. 2016; 150: 73-83.

2. Sævik S. Theoretical and experimental studies of stresses in flexible pipes. Computers \& Structures. 2011; 89 (23-24): 2273-91.

3. Fergestad D, Løtveit SA. Handbook on design and operation of flexible pipes: MARINTEK/ NTNU/4 Subsea; 2014.

4. de Sousa JRM, Campello GC, Kwietniewski CEF, Ellwanger GB, Strohaecker TR. Structural response of a flexible pipe with damaged tensile armour wires under pure tension. Marine Structures. 2014; 39: 1-38.

5. Institute AP. Practice For Flexible Pipe. AN-SI/API Recommended Practice 17B. 2007.

6. Executive HaS. Guidelines for integrity monitoring of unbonded flexible pipe - OTO 98108. Health and Safety Executive, 1998.

7. Zhang Q, Beale D, Adanur S, Broughton RM, Walker RP. Structural analysis of a twodimensional braided fabric. Journal of Textile Institute. 1997; 88(1): 41-52.

8. Clarke T, Jacques R, Bisognin A, Camerini C, Damasceno S, Strohaecker T. Monitoring the structural integrity of a flexible riser during a full-scale fatigue test. Engineering Structures. 2011; 33: 1181-6.

9. Désamais N, Félix-Henry A, Taravel-Condat C, Drouës A. Use of High Strength Steel Wires For Flexible Pipe In Low Sour Service Conditions: Impact On Deep Water Applications. The Seventeenth International Offshore and Polar Engineering Conference. Lisbon, Portugal: International Society of Offshore and Polar Engineers; 2007. p. 1033-8.

10. Kalman M, Belcher J. Flexible Risers with Composite Armor for Deep Water Oil and Gas Production. Composite Materials for Offshore Operations. S. S. Wang, J. G. Williams, and K. H. Lo, Eds., American Bureau of Shipping; 1999. p. 165-179. 
11. Do AT, Lambert A. Qualification of Unbonded Dynamic Flexible Riser with Carbon Fibre Composite Armors. Offshore Technology Conference; 2012.

12. Bezdek A, Kuperberg W. Maximum density space packing with congruent circular cylinders of Infinite Length. Mathematika. 1990; 37(1238): 74-80.

13. Starostin EL. On the perfect hexagonal packing of rods. Journal of Physics: Condensed Matter. 2006; 18(14): S187-S204.

14. ISO. Textiles - woven fabrics - construction - methods of analysis - Part 3: Determination of crimp of yarn in fabric - ISO 7211-3:1984. 2010.

15. ASTM. Standard test methods for flexural properties of unreinforced and reinforced plastics and electrical insulating materials - D790 2003.

16. ASTM. Standard test method for flexural properties of unreinforced and reinforced plastics and electrical insulating materials by four-point bending - D6272 Annual Book of ASTM Standards 2003.

17. ASTM. Flexural properties of polymer matrix composite materials - D7264/D7264M. Annual Book of ASTM Standards 2007.

18. Byun J-H. The analytical characterization of 2-D braided textile composites. Composites Science and Technology. 2000; 60(5): 705-16.

19. Rawal A, Kumar R, Saraswat H. Tensile mechanics of braided sutures. Textile Research Journal. 2012; 82(16): 1703-10.

20. Rawal A, Saraswat H, Kumar R. Tensile response of tubular braids with an elastic core. Composites Part A: Applied Science and Manufacturing. 2013; 47: 150-5.

21. Del Rosso S, Iannucci L, Curtis PT. Experimental investigation of the mechanical properties of dry microbraids and microbraid reinforced polymer composites. Composite Structures. 2015; 125: 50919.

22. Hopper RH, Grant JW, Popper P. Mechanics of a hybrid circular braid with an elastic core. Textile Research Journal. 1995; 65(12): 709-22.

23. Hristov K, Amstrong-Carroll E, Dunn M, Pastore C, Gawayed Y. Mechanical behaviour of circular hybrid braids under tensile loads. Textile Research Journal. 2004; 74(1): 20-6. 
24. ASTM. Standard test method for tensile properties of pultruded glass-fiber-reinforced plastic rod D3916 Annual Book of ASTM Standards; 2002.

25. Hull D, Clyne TW. An introduction to composite materials. Second edition: Cambridge University Press; 1996.

26. Halpin JC, Tsai SW. Environmental factors in composite design. AFML TR 67-423, 1967.

27. Nye JF. Physical properties of crystals - their representation by tensors and matrices: Clarendon Oxford; 1985.

28. Clyne TW. A compressibility-based derivation of simple expressions for the transverse Poisson's Ratio and shear modulus of an aligned long fibre composite. Journal of Material Science and Letters. 1990; 9: 336-9.

29. Dhiman S, Potluri P, Silva C. Influence of binder configuration on 3D woven composites. Composite Structures. 2015; 134: 862-8.

30. Kandelbauer A, Tondi G, Zaske OC, Goodman SH. Unsaturated polyesters and vinyl esters. Third edition: Elsevier Inc.; 2014. 111-72 p.

31. Lo J, Hoa SV. Design, Manufacturing and applications of composites: Proceedings of the sixth joint Canada-Japan workshop on composites: DEStech Publications; 2006.

32. Kennedy A, Shipway P. Chapter 2: Materials and processing. In: Clifford M, Brook R, Howe A, Kennedy A, McWilliam S, Pickering S, et al., editors. An introduction to mechanical engineering Part 1: CRC Press; 2006.

33. Roseman M, Martin R, Morgan G. 10 - Composites in offshore oil and gas applications. In: Summerscales JG-J, editor. Marine applications of advanced fibre-reinforced composites: Woodhead Publishing; 2016, 233-57.

34. DSM. Dyneema ${ }^{\circledR}$ high-strength, high-modulus polyethylene fiber SK 78. In: Brand D, editor. 2008.

35. Chocron S, Kirchdoerfer T, King N, Freitas CJ. Modelling of fabric impact with high speed imaging and nickel-chromium wires validation. The $26^{\text {th }}$ International Symposium on Ballistics; Miami, Florida, 2011.

36. Prtitchard G. An introduction to plastics for non-specialists. Prtitchard G, editor. Cambridge, England: Woodhead Publishing Limited; 1999. 
37. Pipes RB, Pagano NJ. Interlaminar stresses in composite laminates under uniform axial extension. Journal of Composite Materials. 1970; 4: 538-48.

38. Hannemann MM. Shelling hexahedral complexes for mesh generation. Journal of Graph Algorithm and Applications. 2001; 5(5): 55-91.

39. Schonning A, Oommen B, Ionescu I, Conway T. Hexahedral mesh development of free-formed geometry: The human femur exemplified. Computer Aided Design. 2009; 41(8): 566-72.

40. Benzley S.E, Ernest Perry, Karl Merkley, Brett Clark, Sjaardema G. A comparison of allhexahedral and all-tetrahedral finite element meshes for elastic and elasto-plastic analysis. International meshing roundtable; Sandia National Laboratories, 1995, 179-91.

41. Vautard F, Xu L, Drzal L.T. Carbon fibre-vinyl ester interfacial adhesion improvement by the use of a reactive epoxy coating. In Daniel I.M., Gdoutos E.E, and Rajapakse Y.D.S., editor. Major Accomplishments in Composite Materials and Sandwich Structures: Springer Netherlands: Dordrecht 2010; p. 27-50.

42. Banerjee A, Sun L, Mantell SC, Cohen D. Model and experimental study of fiber motion in wet filament winding. Composites Part A: Applied Science and Manufacturing. 1998; 29(3): 251-63.

43. Roy SS, Zao W, Potluri P. Influence of Braid Carrier Tension on Carbon Fibre Braided Preforms. In: Kyosev Y, editor. Recent Developments in Braiding and Narrow Weaving. Cham: Springer International Publishing; 2016. p. 91-102.

44. Potluri P, Manan A, Francke M, Day RJ. Flexural and torsional behaviour of biaxial and triaxial braided composite structures. Composite Structures. 2006; 75(1-4): 377-86.

45. Ahmadi MS, Johari MS, Sadighi M, Esfandeh M. An experimental study on mechanical properties of GFRP braid-pultruded composite rods. Express Polymer Letters. 2009; 3(9): 560-8.

46. Garoushi S, Lassila LVJ, Vallittu PK. The effect of span length of flexural testing on properties of short fiber reinforced composite. Journal of Materials Science: Materials in Medicine. 2011; 23(2): 325-8. 


\section{Image captions}

Fig. 1: Hybrid wire armour wires with different over-braided sleeve configurations

Fig. 2: Multi-scale modelling methodology employed for hybrid composite armour wires

Fig. 3: Material orientation for (a) homogenised composite rod, (b) homogenised orthotropic over-braid shell, and (c) the whole model

Fig. 4: A cross-section of the pultruded composite rod showing a matrix-rich surface

Fig. 5: A schematic of the test setup used for calculating the coefficient of friction

Fig. 6: A schematic representation of the boundary conditions used for: (a) torsional, (b) three-point flexural, and (c) four-point flexural tests

Fig. 7: Comparison of the normalised torsional rigidities of the hybrid wires

Fig. 8: The von Mises stress (MPa) distribution for $45^{\circ}$ braid angle and diamond braid topology at $3 \% \mathrm{~m}$

twist: (a) without the equivalent hoop pressure, and (b) with the equivalent hoop pressure.

Fig. 9: Comparison of the normalised flexural behaviour (three-point flexure) of the hybrid wires

Fig. 10: The von Mises stress (MPa) distribution for $45^{\circ}$ braid angle with diamond topology for a mid-span deflection of $2.5 \mathrm{~mm}$ in three-point flexure: (a) without hoop pressure, and (b) with hoop pressure.

Note: The von Mises stresses are used to show the stress distribution; the parameter SNEG (fraction = -1)

represents the surface stresses in contact with the rods

Fig. 11: Comparison of the normalised flexural behaviour (four-point flexure) of the hybrid wires

Fig. 12: The von Mises (MPa) stress distribution for $45^{\circ}$ braid angle with diamond topology for a mid-span deflection of $2.5 \mathrm{~mm}$ in four-point flexure: (a) without hoop pressure, and (b) with hoop pressure. Note: The von Mises stresses are used to show the stress distribution; the parameter SNEG (fraction = -1) represents the surface stresses in contact with the rods

Fig. 13: The effect of the coefficient of friction in the hybrid wires analysed using the multi-scale model Fig. 14: The effect of gauge length on the torsional and flexural rigidities analysed using the multi-scale model 


\section{Table captions}

Table 1: Experimentally measured structural properties of over-braids

Table 2: Elastic properties of fibre and matrix in the composite rod [29-31]

Table 3: Elastic properties of composite rods

Table 4: The properties of UHMW-PE fibres [34-36], and the calculated properties of UHMW-PE tows

Table 5: The homogenised properties of the over-braid sleeves for different configurations

Table 6: Equivalent hoop pressures for different braid topologies due to braid tow tensions 


\section{ACCEPTED MANUSCRIPT}

\begin{tabular}{|c|c|c|c|c|c|c|}
\hline Type & $\begin{array}{c}\text { Braid } \\
\text { topology }\end{array}$ & $\begin{array}{c}\text { Braid } \\
\text { angle } \\
\left({ }^{\circ}\right)\end{array}$ & $\begin{array}{c}\text { Braid } \\
\text { crimp } \\
(\%)\end{array}$ & $\begin{array}{c}\text { Crimp } \\
\text { angle } \\
\left({ }^{\circ}\right)\end{array}$ & $\begin{array}{c}\text { Braid } \\
\text { thickness } \\
(\mathrm{mm})\end{array}$ & $(\mathrm{mm})$ \\
\hline 1 & $1 / 1$ & 30 & $3.23 \pm 0.34$ & $14.89 \pm 0.77$ & $0.34 \pm 0.01$ & $2.61 \pm 0.06$ \\
\hline 2 & $1 / 1$ & 45 & $3.62 \pm 0.28$ & $16.04 \pm 0.54$ & $0.36 \pm 0.08$ & $1.98 \pm 0.08$ \\
\hline 3 & $1 / 1$ & 55 & $6.48 \pm 0.79$ & $20.62 \pm 1.41$ & $0.42 \pm 0.07$ & $1.55 \pm 0.04$ \\
\hline 4 & $2 / 2$ & 30 & $2.64 \pm 0.39$ & $13.31 \pm 1.03$ & $0.33 \pm 0.05$ & $3.47 \pm 0.06$ \\
\hline 5 & $2 / 2$ & 45 & $3.61 \pm 0.45$ & $16.04 \pm 2.69$ & $0.35 \pm 0.04$ & $2.45 \pm 0.01$ \\
\hline 6 & $2 / 2$ & 55 & $5.55 \pm 0.46$ & $19.48 \pm 1.80$ & $0.41 \pm 0.06$ & $1.95 \pm 0.04$ \\
\hline
\end{tabular}

\pm Standard deviation 


\section{ACCEPTED MANUSCRIPT}

\begin{tabular}{|c|c|c|c|}
\hline Type & $E_{11}(\mathrm{GPa})$ & $G_{12}(\mathrm{GPa})$ & $v_{12}$ \\
\hline Carbon Fibre & 230 & 24 & 0.27 \\
\hline Vinyl Ester & 2.9 & 1.17 & 0.35 \\
\hline
\end{tabular}




\section{ACCEPTED MANUSCRIPT}

\begin{tabular}{|c|c|c|c|c|c|c|l|l|}
\hline $\begin{array}{c}E_{11} \\
(G P a)\end{array}$ & $\begin{array}{c}E_{22} \\
(G P a)\end{array}$ & $\begin{array}{c}E_{33} \\
(G P a)\end{array}$ & $\begin{array}{c}G_{12} \\
(G P a)\end{array}$ & $\begin{array}{c}G_{13} \\
(G P a)\end{array}$ & $\begin{array}{c}G_{23} \\
(G P a)\end{array}$ & $v_{12}$ & $v_{13}$ & $v_{23}$ \\
\hline $110.85 \pm 1.65^{*}$ & 11.24 & 11.24 & $2.42 \pm 0.10^{*}$ & 2.42 & 3.77 & 0.30 & 0.30 & 0.50 \\
\hline
\end{tabular}

* Experimentally determined 


\section{ACCEPTED MANUSCRIPT}

\begin{tabular}{|c|c|c|c|c|c|c|c|c|c|}
\hline Type & $E_{11}$ & $E_{22}$ & $E_{33}$ & $G_{12}$ & $G_{13}$ & $G_{23}$ & $v_{12}$ & $v_{13}$ & $v_{23}$ \\
& $(G P a)$ & $(G P a)$ & $(G P a)$ & $(G P a)$ & $(G P a)$ & $(G P a)$ & & & \\
\hline Fibres & 116 & - & - & 0.95 & - & - & 0.29 & - & - \\
\hline Tows* & 81.41 & 3.83 & 3.83 & 0.59 & 0.59 & 0.64 & 0.32 & 0.32 & 0.78 \\
\hline
\end{tabular}

* Calculated using micro-mechanical models 


\section{ACCEPTED MANUSCRIPT}

\begin{tabular}{|c|c|c|c|c|c|c|c|c|c|c|c|}
\hline Type & $\begin{array}{c}\text { Braid } \\
\text { angle } \\
\left({ }^{\circ}\right)\end{array}$ & Topology & $\bar{E}_{11}$ & $\bar{E}_{22}$ & $\bar{E}_{33}$ & $\bar{G}_{12}$ & $\bar{G}_{13}$ & $\bar{G}_{23}$ & & & \\
$(G P a)$ & $(G P a)$ & $(G P a)$ & $(G P a)$ & $(G P a)$ & $(G P a)$ & $\bar{v}_{12}$ & $\bar{v}_{13}$ & $\bar{v}_{23}$ \\
\hline 1 & 30 & $1 / 1$ & 2.53 & 1.54 & 1.84 & 1.43 & 0.53 & 0.61 & 0.67 & 0.39 & 0.23 \\
\hline 2 & 45 & $1 / 1$ & 1.05 & 1.05 & 1.47 & 1.30 & 0.49 & 0.49 & 0.65 & 0.26 & 0.37 \\
\hline 3 & 55 & $1 / 1$ & 0.88 & 0.90 & 0.99 & 1.02 & 0.57 & 0.58 & 0.48 & 0.40 & 0.38 \\
\hline 4 & 30 & $2 / 2$ & 2.64 & 1.54 & 1.87 & 1.50 & 0.52 & 0.62 & 0.67 & 0.39 & 0.25 \\
\hline 5 & 45 & $2 / 2$ & 1.08 & 1.07 & 1.53 & 1.38 & 0.50 & 0.49 & 0.66 & 0.25 & 0.36 \\
\hline 6 & 55 & $2 / 2$ & 0.95 & 0.98 & 1.02 & 1.12 & 0.57 & 0.55 & 0.48 & 0.38 & 0.39 \\
\hline
\end{tabular}




\section{ACCEPTED MANUSCRIPT}

\begin{tabular}{|c|c|c|c|c|}
\hline Type & $\begin{array}{c}\text { Braid angle } \\
\left({ }^{\circ}\right)\end{array}$ & Topology & $\begin{array}{c}\text { Tension } \\
(\mathrm{N})\end{array}$ & $\begin{array}{c}\text { Equivalent hoop pressure } \\
(\mathrm{MPa})\end{array}$ \\
\hline 1 & 30 & $1 / 1$ & 1.82 & 0.04 \\
\hline 2 & 45 & $1 / 1$ & 1.78 & 0.13 \\
\hline 3 & 55 & $1 / 1$ & 1.76 & 0.22 \\
\hline 4 & 30 & $2 / 2$ & 1.82 & 0.03 \\
\hline 5 & 45 & $2 / 2$ & 1.78 & 0.06 \\
\hline 6 & 55 & $2 / 2$ & 1.76 & 0.10 \\
\hline
\end{tabular}




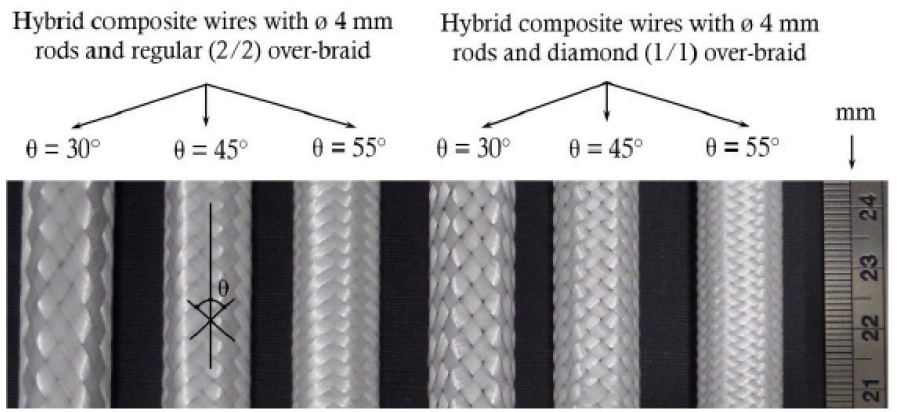




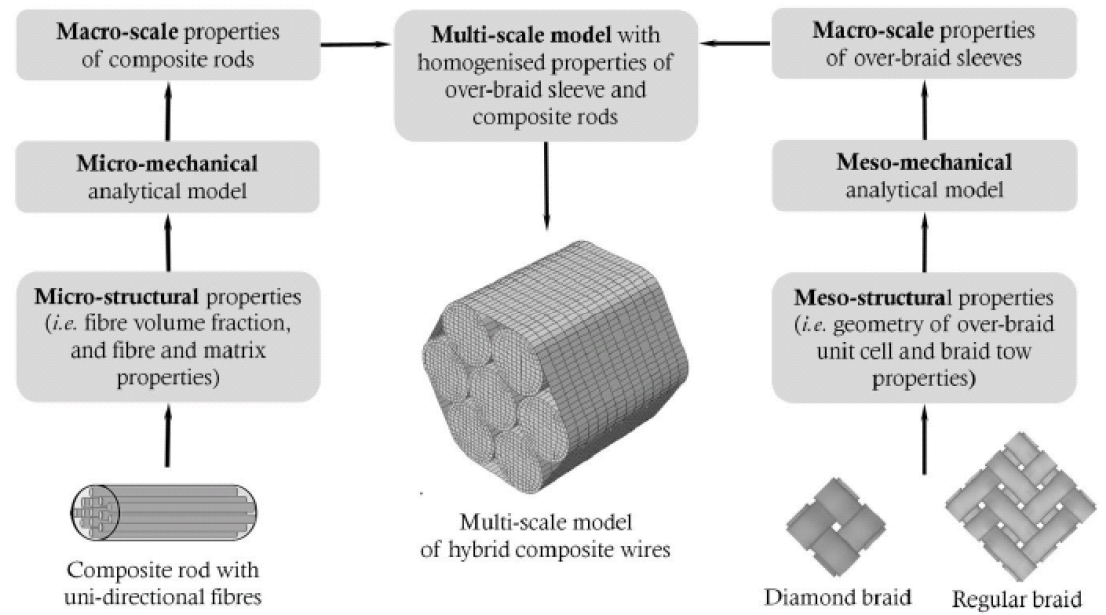




\section{ACCEPTED MANUSCRIPT}
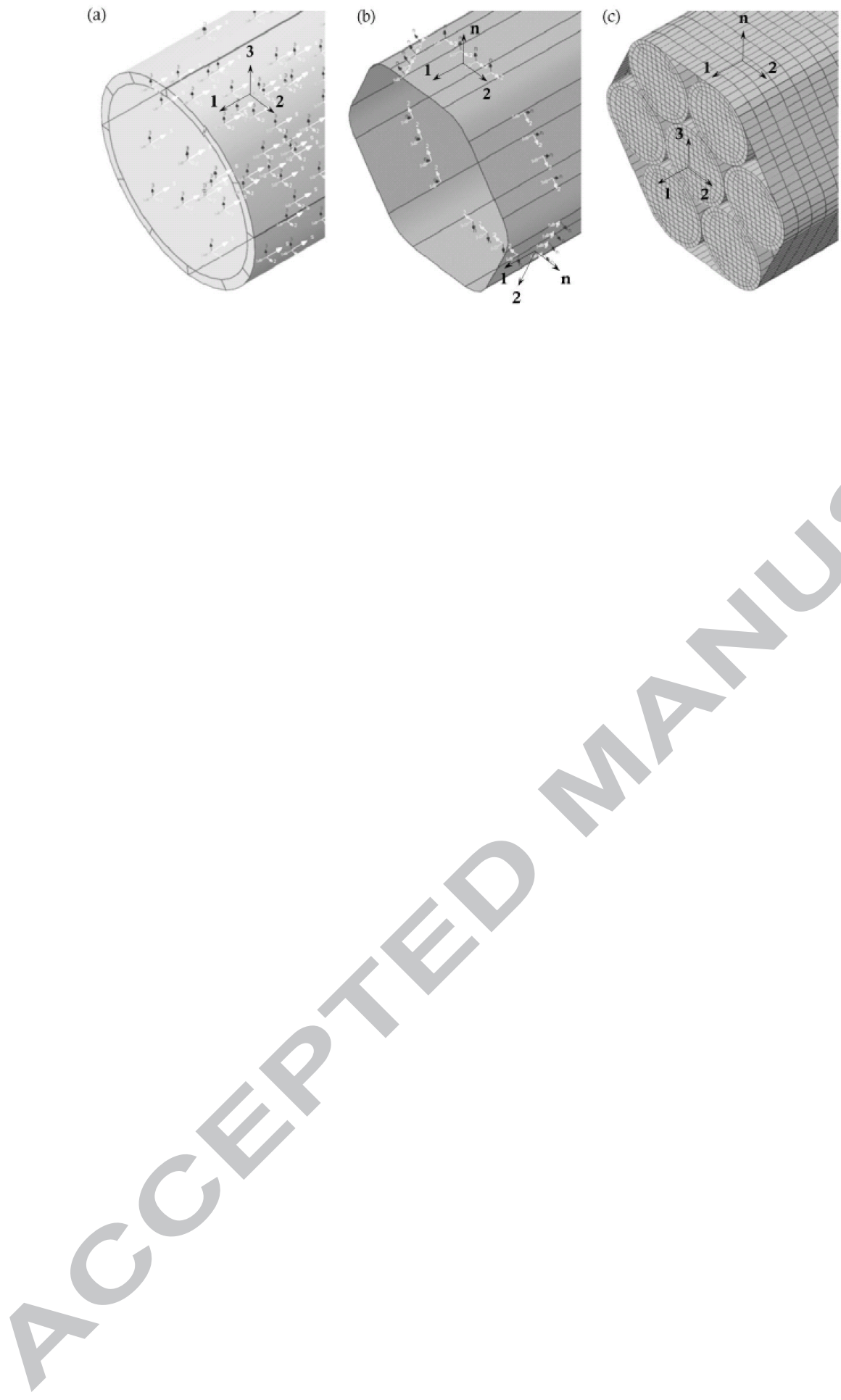


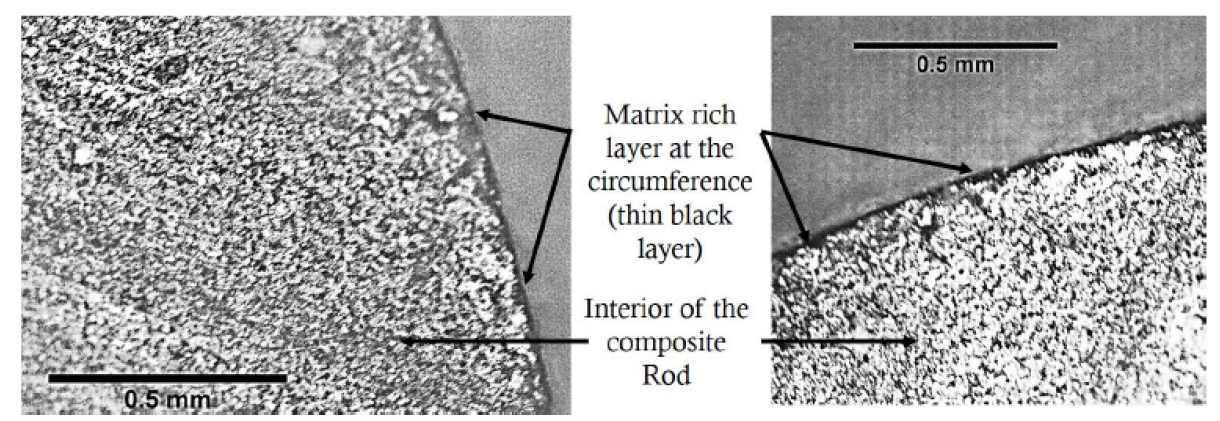




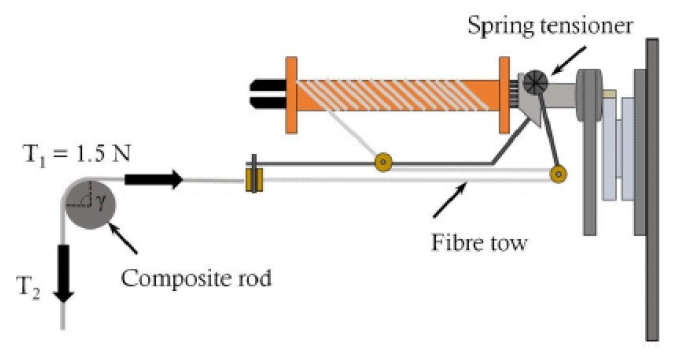


(a)

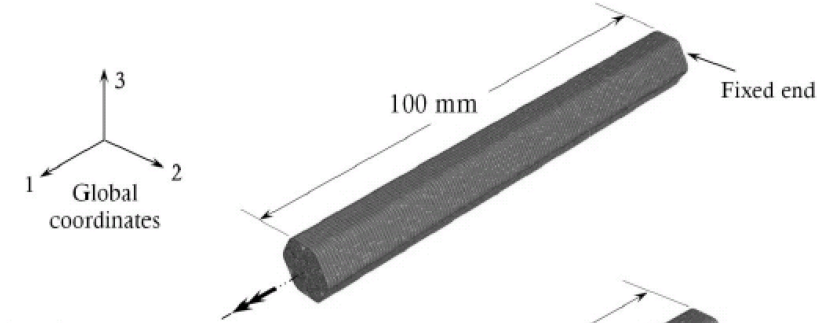

Rotation

(using kinematic coupling)

(b)

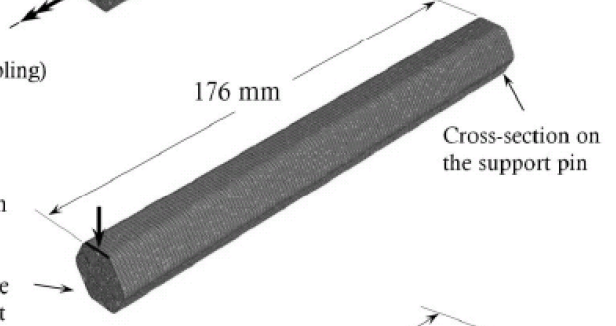

Mid-span cross-section with symmetric

boundary conditions

and in contact with the load pin (displacement applied on the shell edge)

(c)

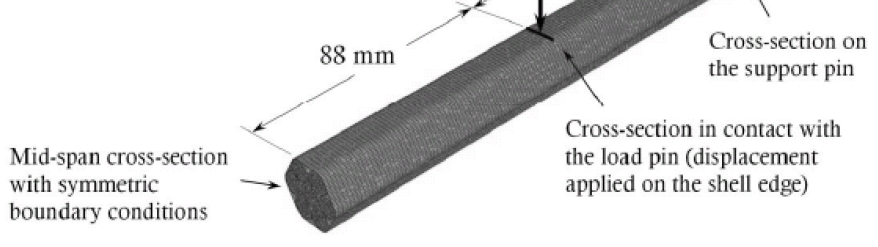




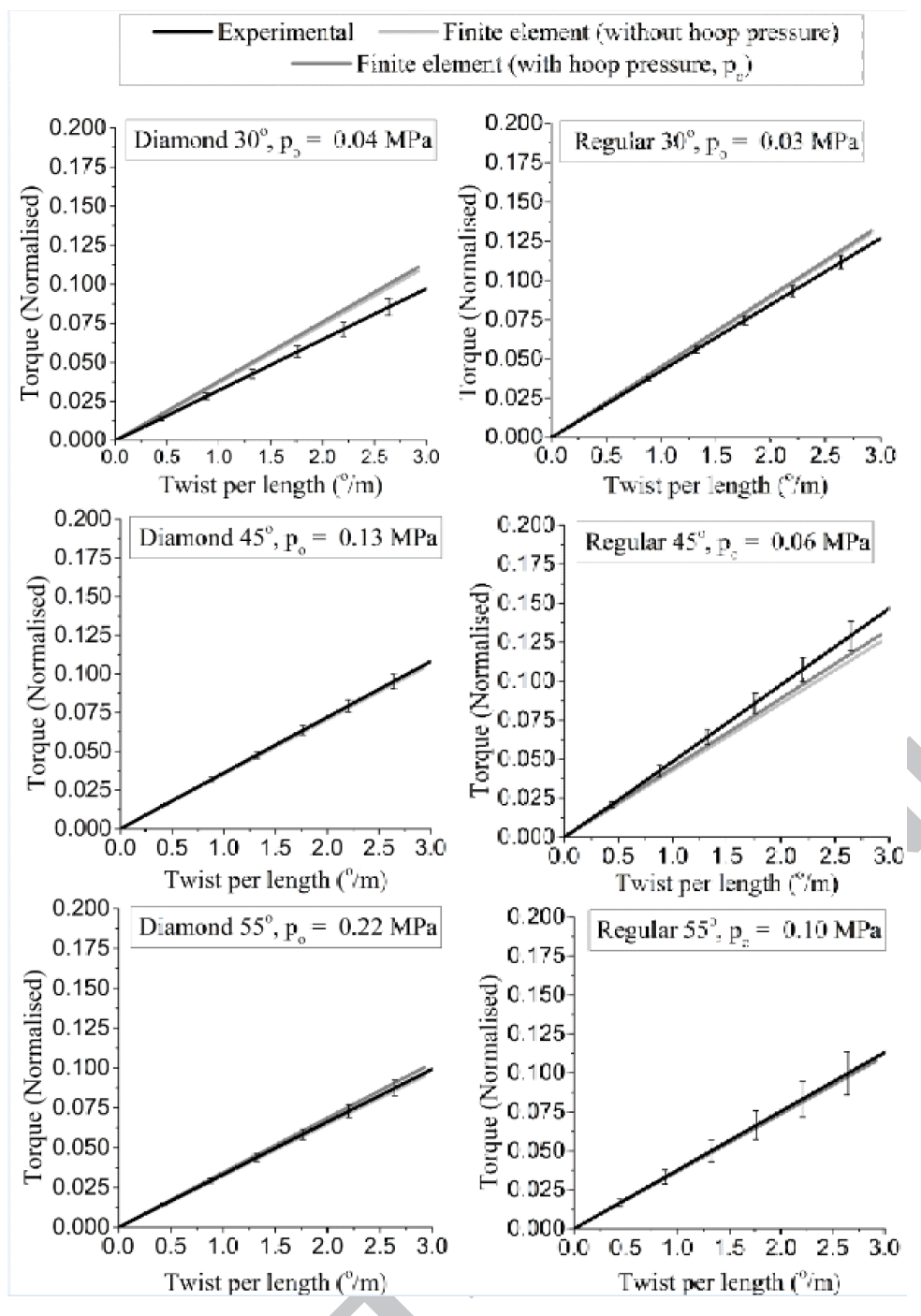



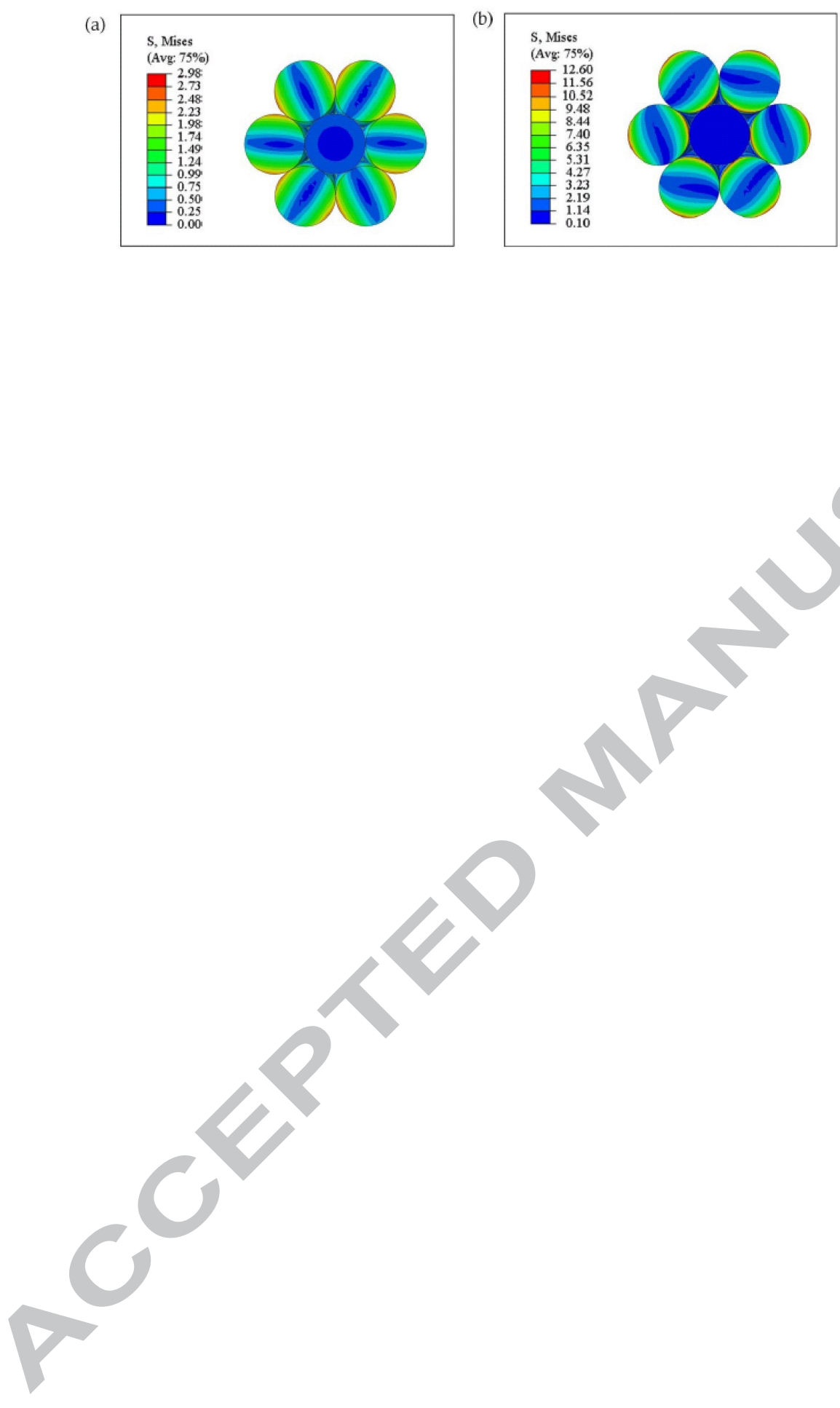


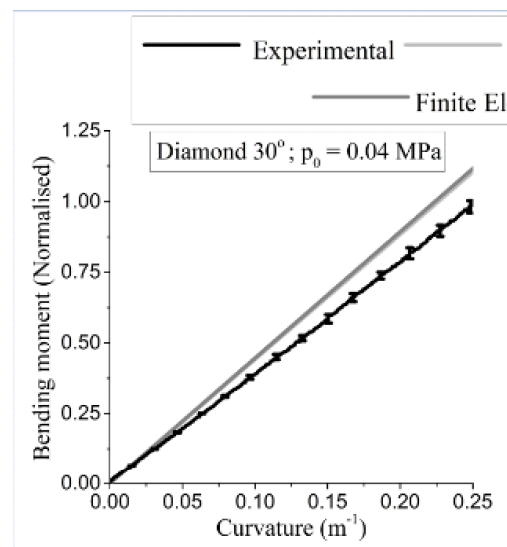

Finite element (without hoop stress)
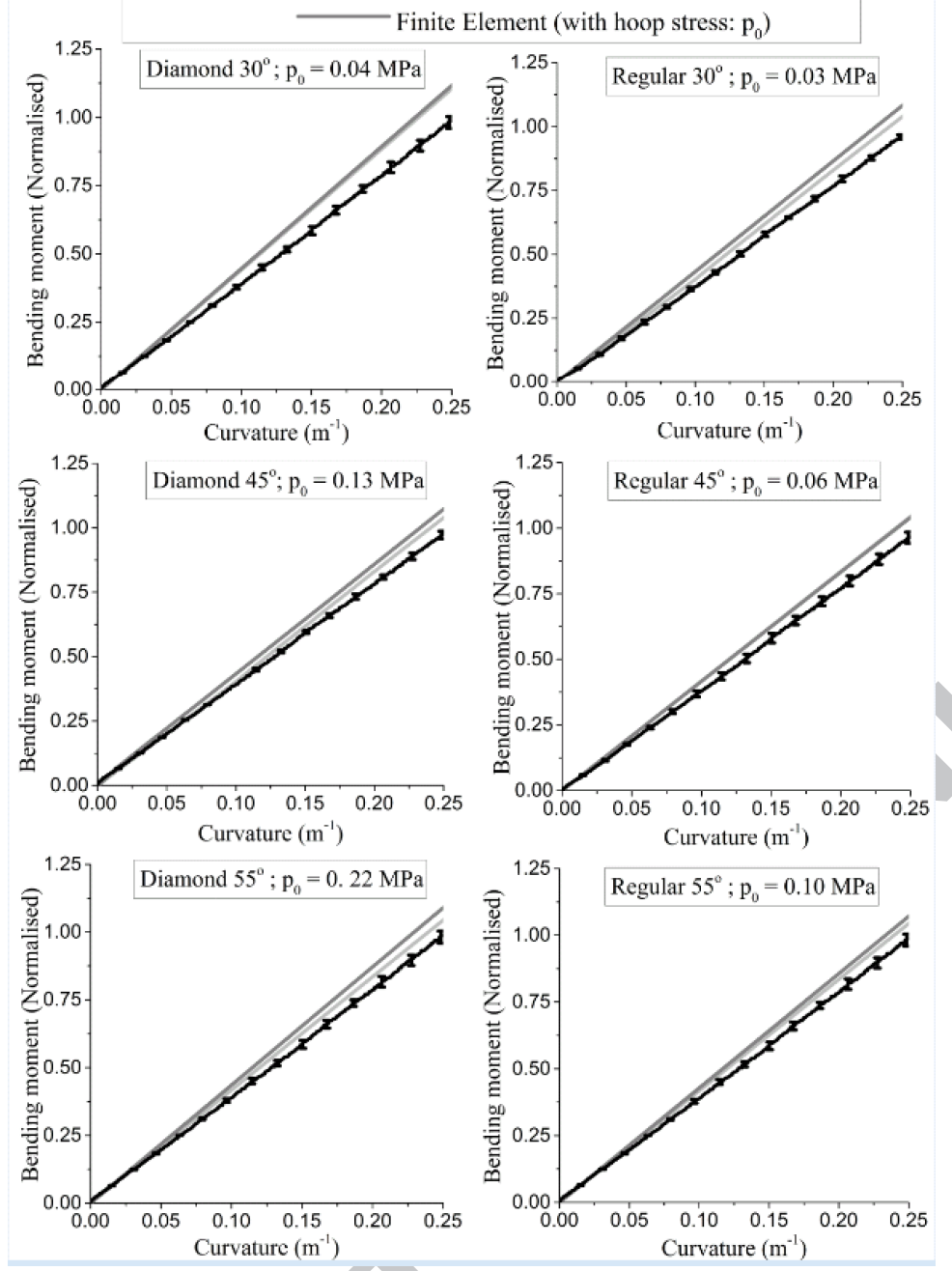
(a)

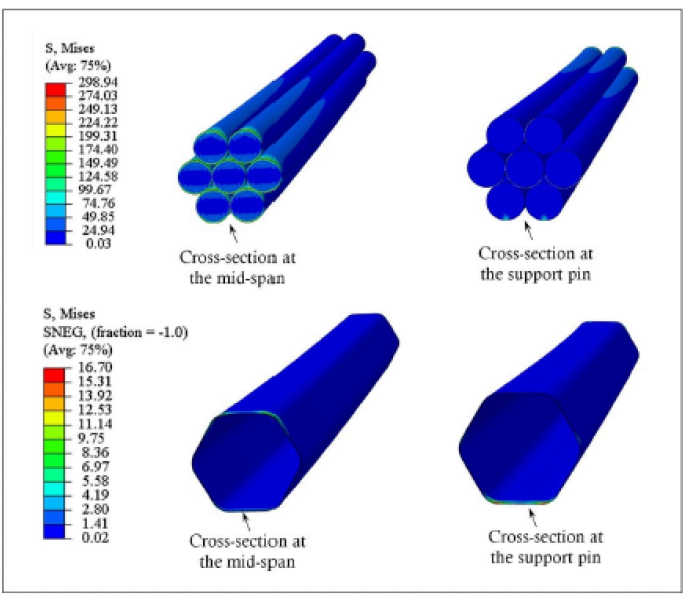

(b)

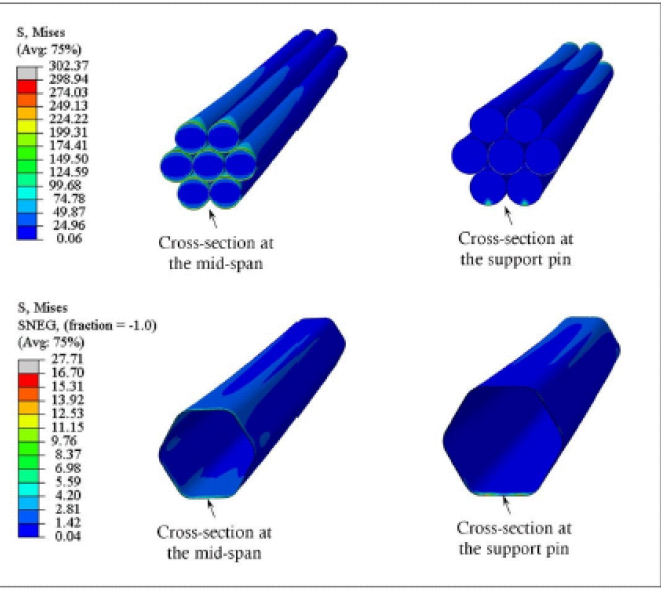




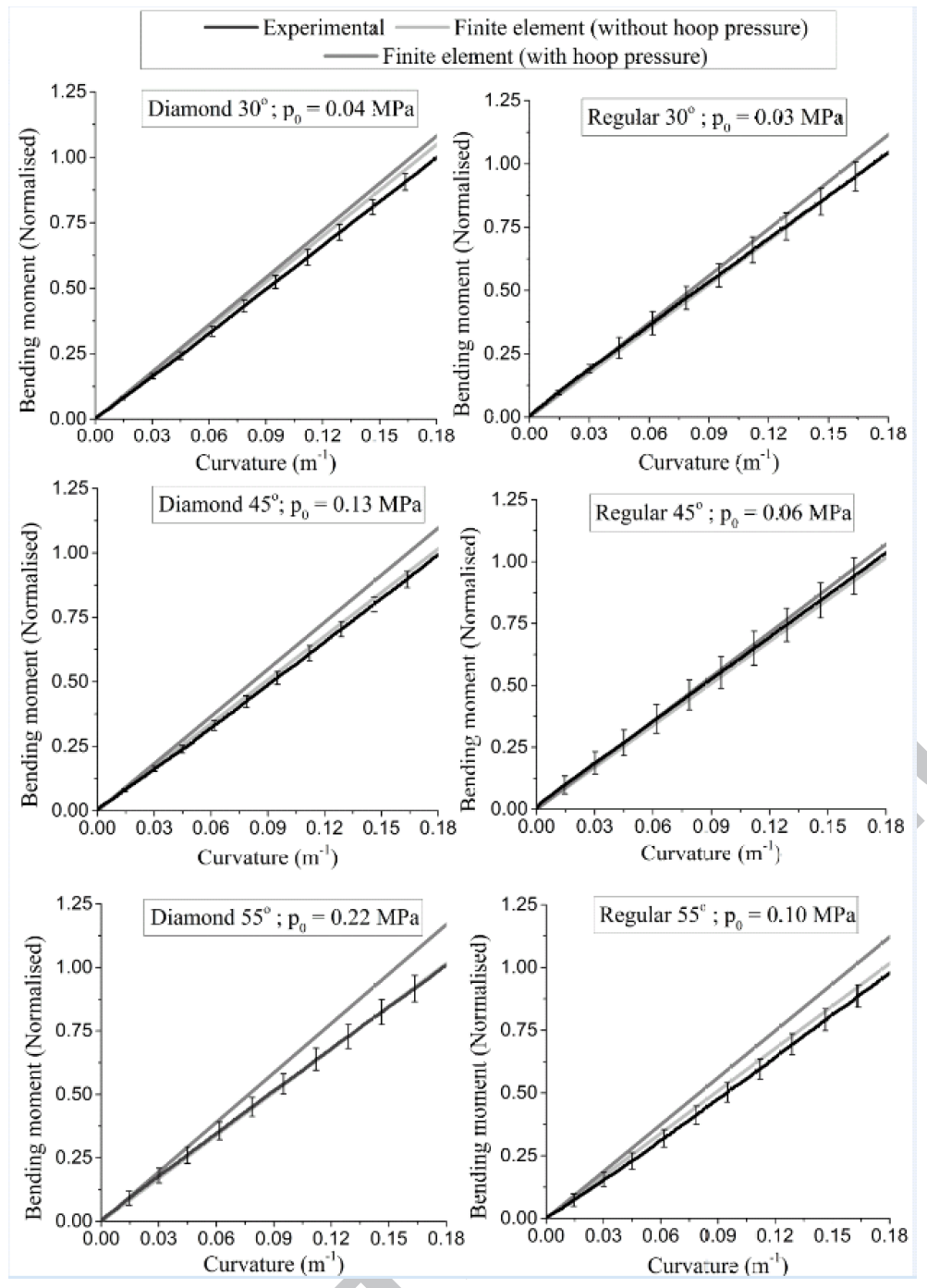



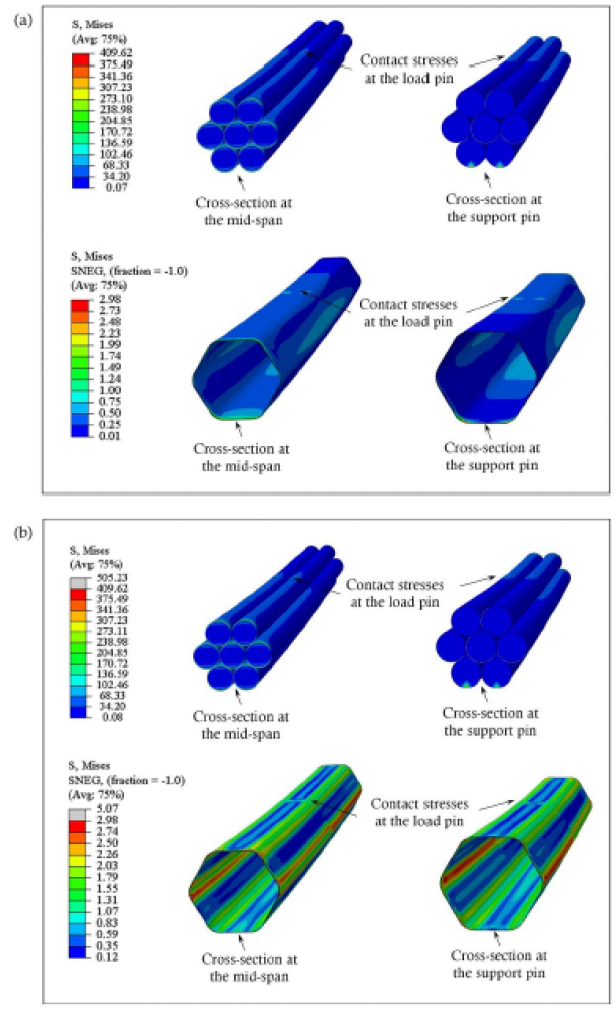

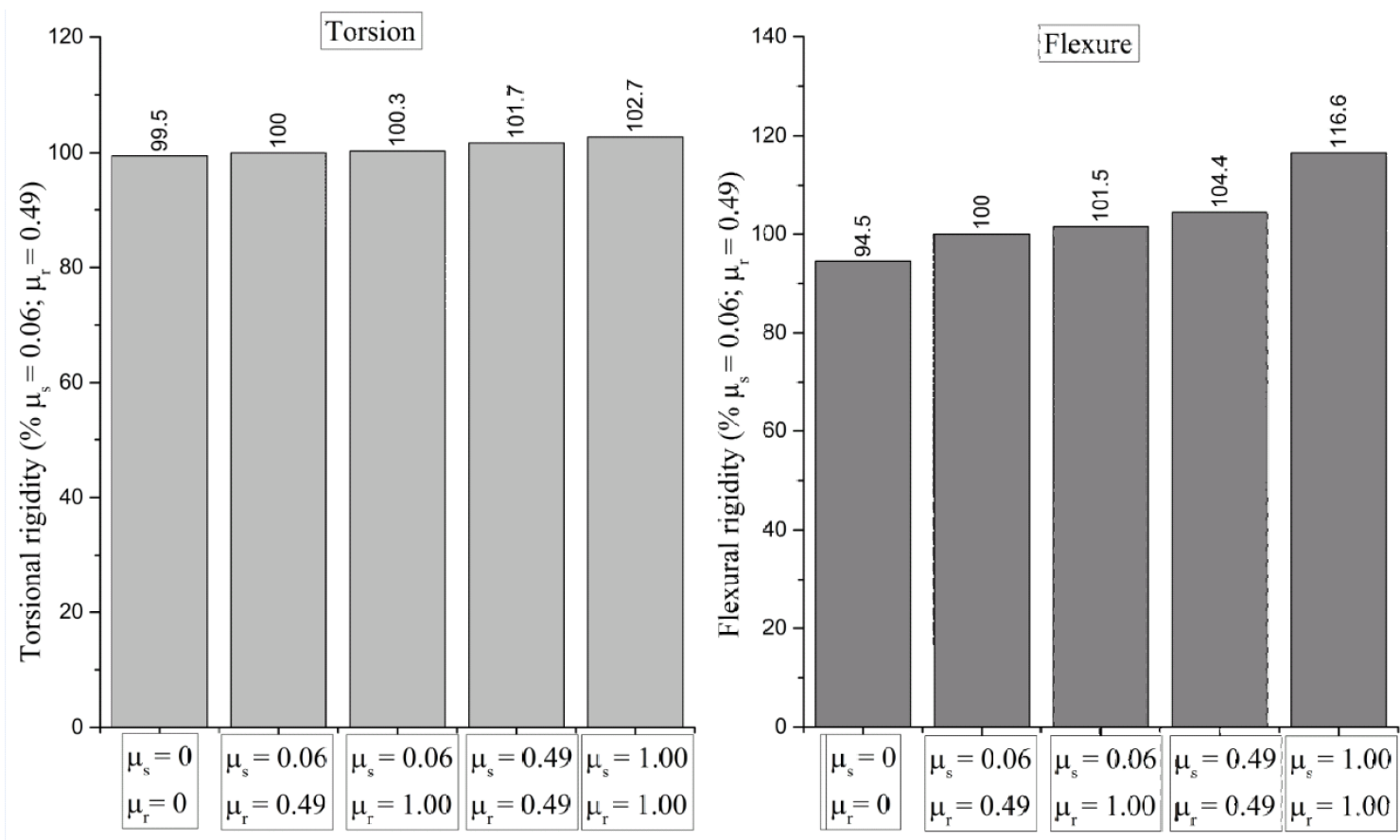

Different coeffecients of friction

\section{Different coeffecients of friction}

$\mu_{\mathrm{s}}$ : Coeffecient of friction between shell and rods; $\mu_{\mathrm{r}}$ : Coeffecient of friction between rods 
Torsion

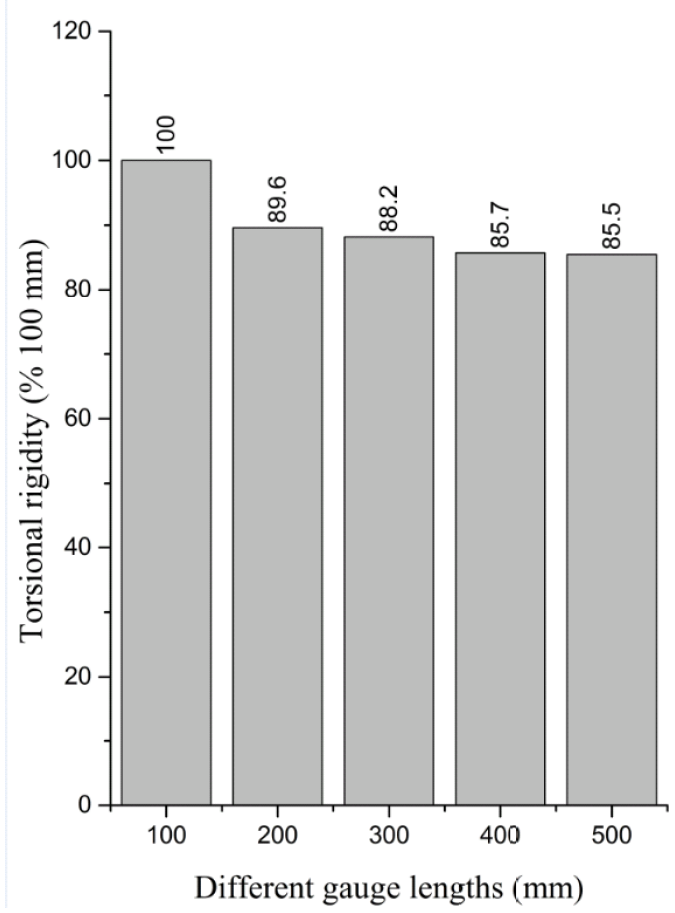

Flexure

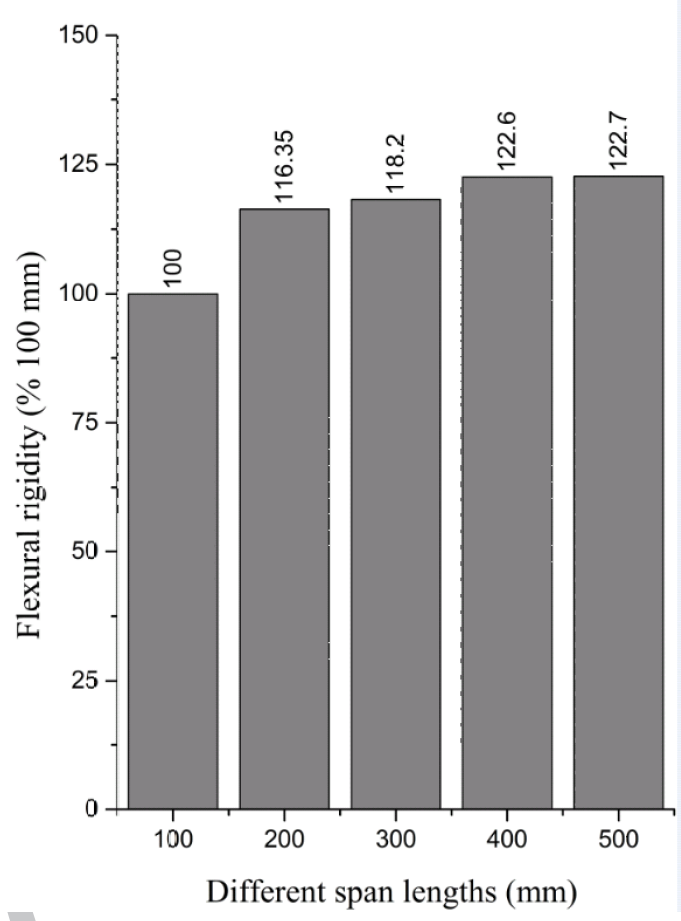

